\title{
Evaluation of attenuative effect of tert-butylhydroquinone against diazinon-induced oxidative stress on hematological indices in male Wistar rats
}

\author{
SAMAN SARGAZI ${ }^{1,2}$, HAMIDREZA GALAVI ${ }^{2}$ and SADEGH ZAREI $^{3}$ \\ ${ }^{1}$ Department of Basic Sciences, Faculty of Veterinary Medicine, Ferdowsi University of Mashhad, Mashhad, \\ Razavi Khorasan 9177948974; ${ }^{2}$ Cellular and Molecular Research Center, Zahedan University of Medical Sciences, \\ Zahedan, Sistan and Baluchestan 9816743181; ${ }^{3}$ Department of Clinical Biochemistry, School of \\ Medicine, Shahid Sadoughi University of Medical Sciences, Yazd 8916978477, Iran \\ Received February 16, 2018; Accepted April 19, 2018
}

DOI: 10.3892/br.2018.1090

\begin{abstract}
Diazinon is an organophosphate toxicant that has been identified to induce oxidative stress within biological systems through altering biochemical and hematological indices, by generating free radicals while deteriorating the cellular antioxidant defense system. The present study was designed to evaluate the effectiveness of tert-butylhydroquinone (TBHQ), a synthetic food additive, in serving as an antioxidant against sub-lethal diazinon-induced oxidative stress in male Wistar rats. Animals were randomly divided into 4 groups: Control (treated with corn oil as a vehicle), diazinon (10 mg/kg/day), TBHQ $(0.028 \mathrm{~g} / \mathrm{kg}$ of diet) and a combination group of TBHQ ( $0.028 \mathrm{~g} / \mathrm{kg}$ of diet) plus diazinon $(10 \mathrm{mg} / \mathrm{kg} / \mathrm{day})$. All animals were treated orally once a day by gastric tube and treatments were continued for 7 weeks. Hematological indices, including red blood cell (RBC) indices and white blood cell (WBC) and platelet counts, were measured at the end of the treatment schedule. On comparison of the treatment groups with the untreated control group, RBC count, hemoglobin (Hb), hematocrit (Hct), mean corpuscular hemoglobin $(\mathrm{MCH})$ and mean corpuscular hemoglobin concentration (MCHC) were significantly decreased in the diazinon and $\mathrm{TBHQ}+$ diazinon groups, while MCHC in the TBHQ group and MCV in the diazinon and TBHQ+diazinon groups were significantly increased. When the diazinon and $\mathrm{TBHQ}+$ diazinon groups were compared with the TBHQ group, RBC, Hb, Hct, and MCHC were significantly decreased whereas MCV was increased in both groups. Additionally, when comparing the TBHQ+diazinon group with the diazinon group, $\mathrm{MCHC}$ was determined to be significantly decreased. The results of the current experiments suggested
\end{abstract}

Correspondence to: Dr Saman Sargazi, Department of Basic Sciences, Faculty of Veterinary Medicine, Ferdowsi University of Mashhad, Azadi Square, Mashhad, Razavi Khorasan 9177948974, Iran E-mail: sgz.biomed@gmail.com

Key words: organophosphate, diazinon, tert-butylhydroquinone, pesticide that TBHQ could not efficiently protect blood cells against diazinon toxicity.

\section{Introduction}

Oxidative stress is generally described as any biochemical or physiological condition that results in an imbalance between the rate of reactive oxygen species (ROS) production and the ability of body antioxidant systems to overcome the disruption caused by these chemically reactive radicals (1). The most common ROS are hypochlorite ion, superoxide anion, hydrogen peroxide and in particular hydroxyl radical, which is considered the most reactive (2). Free radicals typically interact with polyunsaturated fatty acid residues of cell membrane phospholipids, forming lipid peroxides that can further produce mutagenic and carcinogenic malondialdehyde (MDA) in addition to cyclic DNA adducts $(3,4)$. Additionally, oxidative stress has potent effects in the pathogenesis of several clinical conditions including hypertension (5), coronary heart diseases (6) and both type 1 and type 2 diabetes mellitus (7). Regarding the nature of ROS, some are notably toxic and are rapidly detoxicated to less harmful metabolites by a range of cell mechanisms that are either enzymatic or non-enzymatic (8). This conversion is key in affected cells to enable normalization of cell function and metabolism (9).

Organophosphate (OP) compounds consist of a variety of chemicals that are the most toxic among all pesticides to vertebrates and humans (10). However, OPs are still widely used in certain third world countries for agricultural or veterinary interventions as solvents or extreme pressure additives $(11,12)$. In the last twenty years the improper use of OPs has led to toxic resistance, which is of major concern to the environment, animals and human populations (13). Additionally, it has been reported that residual quantities of OPs may be detected in plants, tissues of organisms and foods products (7). OPs are generally rapidly absorbed by the skin or mucous membranes of the oral cavity during inhalation (8), which mediates the onset of adverse reactions. Furthermore, OPs are considered to have damaging effects on the urinary (14) and reproductive (15) systems as for other vital organs. 
The neurobehavioral development of fetuses and children is considered to be one of the disorders with an undetermined association with OP exposure even at very low levels. OPs are classified into four principal groups, namely as herbicides (trichlorfon), ophthalmic glaucoma agents, certain types of nerve gases (VX and sarin) and most notably, insecticides, for which there is a marked number (including diazinon, malathion and parathion) (16). Although it has been demonstrated that OPs inhibit the activity of acetylcholinesterase (AChE), the main enzyme responsible for acetylcholine (ACh) degradation (17), further study revealed that the toxic consequences of OP exposure may be due to induction of oxidative stress (18). The acute toxicity of OPs manifests as cholinergic damage, which is associated with irreversible covalent inhibition of cholinesterase activity in the central nervous system (19). As a result, accumulated $\mathrm{ACh}$ is not degraded and nicotinic receptors are activated, and consequently cell death is prompted (20).

Diazinon [O,O-diethyl-O-(2-isopropyl-6-methyl-4pyrimidinyl)phosphorothioate] is a colorless liquid and also a thiophosphoric acid derivative that is ordinarily used to control pests and insects (21). There is a range of data indicating the association between diazinon toxicity and altered liver enzyme function and biochemical and hematological parameters (22-24). As mentioned, the main mechanism by which diazinon induces acute intoxication is AChE inhibition, which causes an abnormal accumulation of ACh in the synaptic cleft (25). Exposure to sub-lethal doses of diazinon is associated with chronic toxicity, and ultimately elevated lipid peroxidation and decreased antioxidant enzyme activity $(10,26)$. Furthermore, since diazinon is fat soluble, prolonged toxicity should be considered if a substantial quantity of diazinon is stored in fatty tissues (27). By contrast, it has been established that antioxidants as scavenger substances are capable of neutralizing ROS or inhibiting free radical formation, and thus effectively protect cells against oxidative stress-inducing agents including OPs (28). There are two major types of antioxidants: Enzymatic and non-enzymatic. Over previous years, vitamins $\mathrm{C}$ and $\mathrm{E}$ and numerous other natural and synthetic compounds functioning as non-enzymatic antioxidants have been used against cellular oxidative stress induction caused by OP substances (29).

There are a number of synthetic antioxidants that are permitted by the US Food and Drug Administration for use in food products (30). Among edible synthetic antioxidants, tert-butylhydroquinone (TBHQ) is primarily used as a food additive for unsaturated vegetable oils (31). TBHQ is considered to mainly function via induction of nuclear translocation of the transcription factor NF-E2-related factor 2 (Nrf2), which in turn potently regulates the gene expression of certain antioxidant enzymes, including heme oxygenase-1 and glutathione S-transferase (32).

Despite the importance of OP toxicity as a health issue and the risk of constant exposure of farmers to OP substances, particularly diazinon, there is no sufficient data regarding the combined effects of diazinon and TBHQ on hematological indices alteration. Therefore, the present study aimed to evaluate the effects of sub-lethal doses of the OP insecticide diazinon on hematological parameters, and to investigate the possible attenuative role of TBHQ against ROS production in Wistar rats.

\section{Materials and methods}

Chemicals. All chemicals used were of pure analytical grade. Diazinon, purity 99\%, was obtained from Merck KGaA (Darmstadt, Germany) and TBHQ was supplied by Sigma-Aldrich (Merck KGaA).

Animals. A total of 28 adult male Wistar rats weighing 250-300 g (mean age, 18 \pm 2 weeks old), purchased from the central animal house facility at Mashhad University of Medical Sciences (Mashhad, Iran), were utilized for the current cross-sectional experimental study. The rats were caged (with a mean number of 4 animals per cage; maximum, $\mathrm{n}=6$ ) with paddy husk bedding under a 12-h light/dark cycle (light period from 6.30 a.m. to 6.30 p.m.), $23 \pm 2{ }^{\circ} \mathrm{C}$ and $60 \%$ humidity. The rats were acclimatized for at least 7 days prior to randomizing into experimental groups. The animals were permitted access to a commercial pellet diet (manufactured in Javaneh Khorasan, Mashhad, Iran) and tap water ad libitum. All animals received human care and the protocols of the experiment were approved by the Animal Welfare Committee of the School of Veterinary Medicine, Ferdowsi University of Mashhad (Mashhad, Iran).

Experimental protocol and drugs. The 28 male Wistar rats were categorized randomly in 4 equal-sized groups $(n=7$ per group) comprising of a control group and three experimental groups, as follows: Group 1 (Control), which received corn oil as a vehicle for both TBHQ and diazinon, once a day via gavage tube; group 2 (diazinon-treated group), which was administrated diazinon $(10 \mathrm{mg} / \mathrm{kg} / \mathrm{day})$ in corn oil, once a day via gastric tube, with this selected dose having been used in previous studies and demonstrated efficacy in altering the biochemical and hematological parameters of male Wistar rats $(24,29)$; group 3 (TBHQ-treated group), in which TBHQ was orally administrated at a dose of $0.028 \mathrm{~g} / \mathrm{kg}$ of diet (in corn oil), which has previously been indicated to have antioxidant effects (33); and group 4 (TBHQ+diazinon), in which diazinon and TBHQ (also in corn oil) were orally administrated at the aforementioned doses $(10 \mathrm{mg} / \mathrm{kg} /$ day of diazinon and $0.028 \mathrm{~g} / \mathrm{kg}$ of diet of TBHQ) once a day via gavage tube.

In attempt to approximate the average daily diet consumption in grams, the food intake of rats was assessed over the 7 days of acclimatization by calculating the difference between intact pre-weighed food and the quantity of food remaining after $24 \mathrm{~h}$ in cages. All rats were non-fasted by the time of oral administration (between 10 and 11 a.m. in the morning). The first treatment day was appointed the first day of the experiment. The volume of treatment solution was equal for all the groups.

At the end of day 49, animals were euthanized. Whole blood samples were immediately collected through cardiac puncture (up to $7 \mathrm{ml}$ was drawn from each rat). Using a Bayer-Advia 120 hematology analyzer (Bayer Corporation, Whippany, NJ, USA), the blood samples with anti-coagulant EDTA were instantly analyzed to evaluate the main hematological indices, namely red blood cell (RBC) count, hemoglobin (Hb) concentration, hematocrit (Hct) levels, white blood cell (WBC) count, mean corpuscular $\mathrm{Hb}(\mathrm{MCH})$, mean corpuscular volume (MCV), mean corpuscular $\mathrm{Hb}$ concentration $(\mathrm{MCHC})$ and platelet count. 


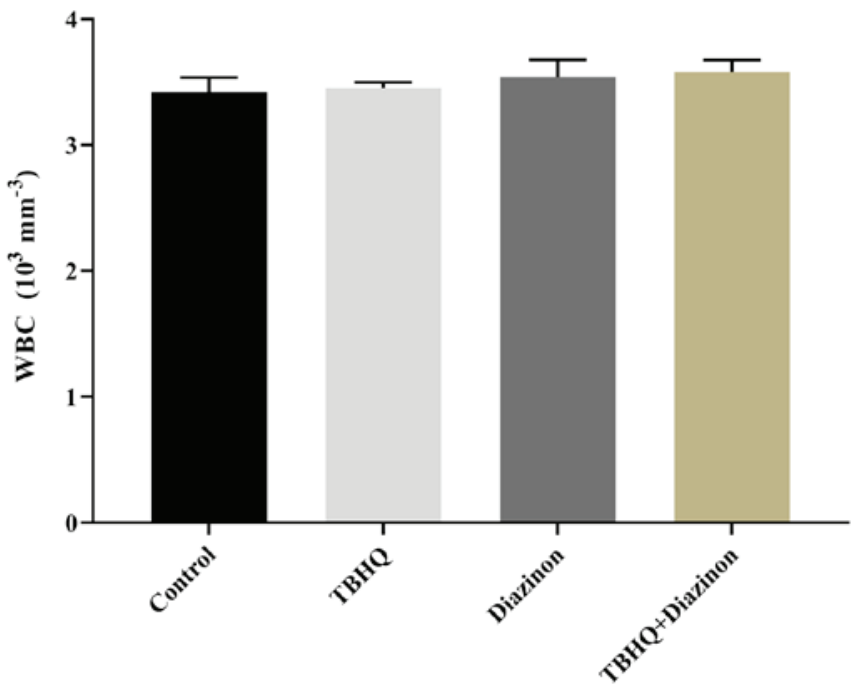

Figure 1. Mean values of WBC count in control, TBHQ and/or diazinon-treated rats. WBC, white blood cell; TBHQ, tert-butylhydroquinone.

Statistical analysis. Statistical analysis was conducted using SPSS version 22 (IBM Corp., Armonk, NY, USA). One-way analysis of variance with post hoc Tukey's tests were used to determine the significance of differences, with $\mathrm{P}<0.05$ considered to indicate statistical significance. The F-test was performed to determine the normal distribution of variances between groups. The results are presented as the mean \pm standard deviation obtained from the 7 animals in each group.

\section{Results}

Comparison of hematological parameters. The results of hematological parameters in the current study were assessed according to three comparisons: i) Compared with the untreated control group; ii) compared with the TBHQ-treated group; and iii) compared with the diazinon-treated group.

WBC count. Comparison of WBC count between the four groups in the current study identified no statistically significant differences, although TBHQ led to a marginal increase in WBC count compared with the untreated control group. This enhancement was observed in the diazinon and combination groups with increased intensity (Fig. 1).

$R B C, H b$ and $H c t$. Notable changes were observed in RBC count, $\mathrm{Hb}$ content and Hct levels in erythrocytes. The number of RBCs was significantly decreased in the diazinon and TBHQ+ diazinon groups compared with in the untreated control and TBHQ groups $(\mathrm{P}<0.001)$. Hb and Hct levels were also significantly decreased in the diazinon and TBHQ+diazinon groups compared with in the control and TBHQ groups ( $\mathrm{P}<0.001$; Fig. 2$)$.

$M C V, M C H$ and $M C H C$. Comparing the untreated control group with the other groups, significant alterations were identified in MCV [diazinon group vs. control group $(\mathrm{P}<0.001)$ and $\mathrm{TBHQ}+$ diazinon group vs. control group $(\mathrm{P}<0.001)$ ], $\mathrm{MCH}$ [diazinon group vs. control group $(\mathrm{P}<0.05)$ and TBHQ+diazinon group vs. control group $(\mathrm{P}<0.05)]$ and $\mathrm{MCHC}$ [TBHQ group vs. control group $(\mathrm{P}<0.05)$, diazinon

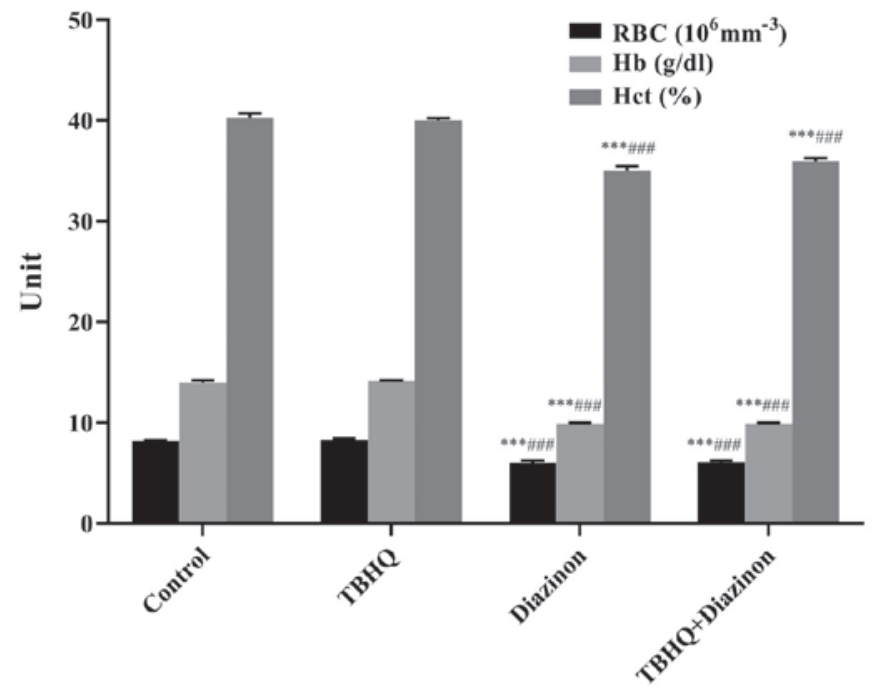

Figure 2. Mean values of $\mathrm{RBC}, \mathrm{Hb}$ and Hct in control, TBHQ and/or diazinon-treated rats. ${ }^{* * *} \mathrm{P}<0.001$ vs. control; ${ }^{\# \#} \mathrm{P}<0.001$ vs. TBHQ. RBC, red blood cell; Hb, hemoglobin; Hct, hematocrit; TBHQ, tert-butylhydroquinone.

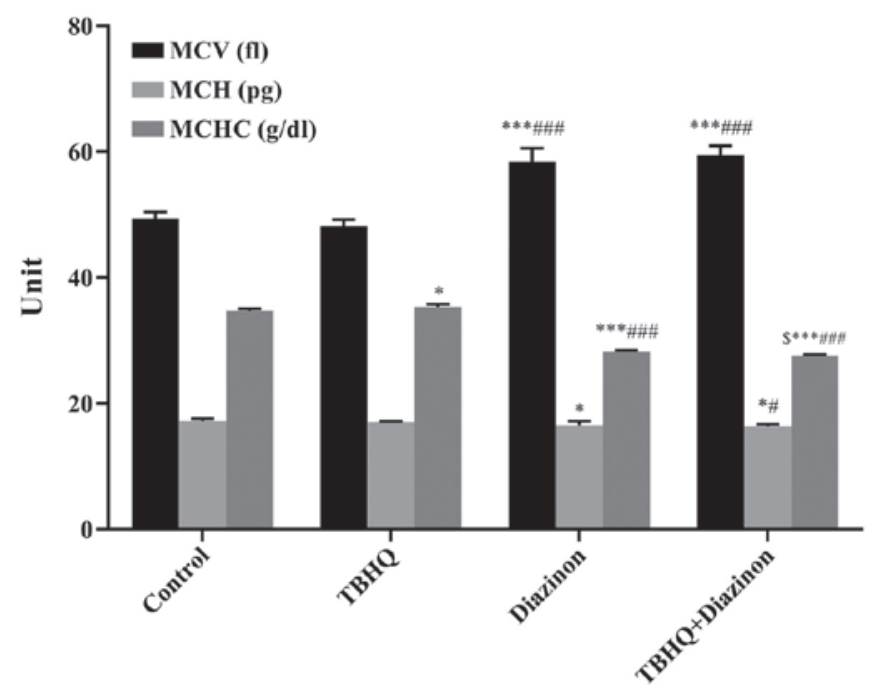

Figure 3. Mean values of $\mathrm{MCV}, \mathrm{MCH}$ and $\mathrm{MCHC}$ in control, TBHQ and/ or diazinon-treated rats. ${ }^{*} \mathrm{P}<0.05,{ }^{* * * *} \mathrm{P}<0.001$ vs. control; ${ }^{\#} \mathrm{P}<0.05,{ }^{\# \# \#} \mathrm{P}<0.001$ vs. TBHQ; ${ }^{\$} \mathrm{P}<0.05$ vs. Diazinon. $\mathrm{MCV}$, mean cell volume; $\mathrm{MCH}$, mean cell hemoglobin; MCHC, mean cell hemoglobin concentration; TBHQ, tert-butylhydroquinone.

group vs. control group $(\mathrm{P}<0.001)$ and $\mathrm{TBHQ}+$ diazinon group vs. control group $(\mathrm{P}<0.001)]$. Significant differences were also identified between the diazinon groups (single and combined treatments) and TBHQ group concerning MCV [diazinon group vs. TBHQ group $(\mathrm{P}<0.001)$ and $\mathrm{TBHQ}+$ diazinon group vs. TBHQ group $(\mathrm{P}<0.001)], \mathrm{MCH}[\mathrm{TBHQ}+$ diazinon group vs. TBHQ group $(\mathrm{P}<0.05)$ ] and MCHC [diazinon group vs. TBHQ group $(\mathrm{P}<0.001)$ and $\mathrm{TBHQ}+$ diazinon group vs. TBHQ group $(\mathrm{P}<0.001)]$. MCHC was the only parameter that significantly differed between the TBHQ+diazinon and diazinon groups $(\mathrm{P}<0.05)$, being significantly decreased in the TBHQ+diazinon group (Fig. 3).

Platelet count. There were no significant differences in platelet number between all four groups ( $\mathrm{P}>0.05$; Fig. 4). 


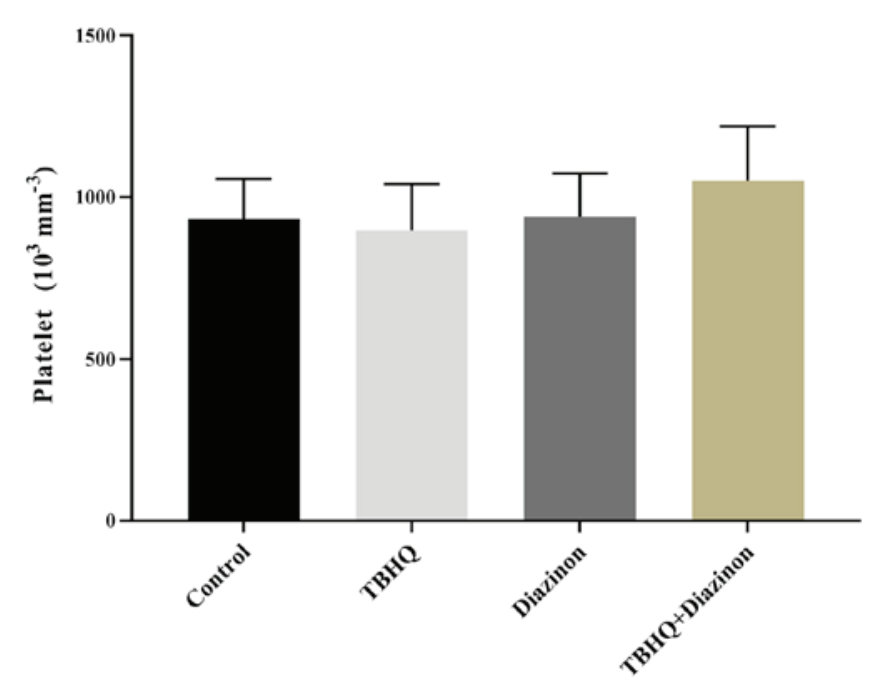

Figure 4. Mean values of platelet count in control, TBHQ and/or diazinontreated rats. TBHQ, tert-butylhydroquinone.

\section{Discussion}

OP toxicity is considered to be among the most important challenges currently faced by agricultural environments, and biological environments in general. Over previous years, a number of types of pesticides have been used for pest and insect control, and the use of OPs has been reported to have among the most potent effects (34). In this regard, OPs are essential for sufficient agricultural yield, and thus their application still continues in certain developing countries (35). Diazinon is widely used as an insecticide for plant protection, and also serves as an ectoparasitic agent for parasitic control in sheep (36). As a consequence, broad distribution of OPs including diazinon in the environment correlates with onset of toxic effects in land and marine animals $(37,38)$. Alongside the natural antioxidants, permitted concentrations of synthetic antioxidants have been demonstrated to exert protective effects against the oxidative stress-induced cytotoxicity (39). In the present study, the attenuative effect of TBHQ against diazinon-induced toxicity with regard to hematological indices was evaluated in 28 male Wistar rats, in which mild oxidative damage was observed following exposure to sub-lethal levels of diazinon, indicated by reductions in $\mathrm{RBC}$ count, $\mathrm{Hb}$ concentration and Hct level.

Primary hematological indices include WBC, RBC and platelet counts. Other parameters including $\mathrm{Hb}, \mathrm{Hct}, \mathrm{MCV}$, $\mathrm{MCH}$ and $\mathrm{MCHC}$ provide specific information on $\mathrm{RBC}$ characteristics such as size and morphology in vertebrates (40). In the current study, TBHQ, Diazinon, or their combination had no significant effect on WBC and platelet numbers, although the compounds had marked influence on RBC-related indices. Notably, RBC count was decreased in male Wistar rats following exposure to diazinon alone or in combination with TBHQ, compared with in the control and TBHQ groups. Reductions in $\mathrm{Hb}$ and Hct were also observed. Other parameters of RBCs including $\mathrm{MCV}, \mathrm{MCH}$ and $\mathrm{MCHC}$ were also influenced following exposure of the rats to the compounds: $\mathrm{MCV}$ was increased following treatment with Diazinon and TBHQ+diazinon compared with in the untreated and TBHQ groups; $\mathrm{MCH}$ was marginally decreased in the diazinon group compared with in the untreated group, and in the TBHQ+diazinon groups compared with in the untreated and TBHQ groups; and MCHC was significantly lower in the untreated group vs. TBHQ group and TBHQ+diazinon group vs. diazinon group. Additionally, MCHC was reduced in the diazinon and TBHQ+diazinon groups compared with in the untreated and TBHQ groups. A possible mechanism for the reduction in $\mathrm{RBC}$ count is that chronic intoxication induced by diazinon leads to oxidation of the membrane phospholipids of the RBC cells, subsequently decreasing $\mathrm{Hb}$ and Hct and effecting related indices including $\mathrm{MCV}, \mathrm{MCH}$, and $\mathrm{MCHC}$; while the antioxidant of the present study (TBHQ) did not efficiently protect the morphology of RBCs against $10 \mathrm{mg} / \mathrm{kg} /$ day diazinon. Regarding WBC and PLT counts, the related mechanism cannot be concluded due to contradictory results of previous studies mentioned below.

Many investigations have been conducted concerning the effect of diazinon toxicity on hematological indices, which have yielded contradictory data $(41,42)$; nevertheless, the current results do not contradict the findings of most previous investigations mentioned above. However, to the best of our knowledge, there is no published report on utilization of TBHQ as an antioxidant substance and its combination with diazinon in effecting hematological parameters.

According to previous experiments performed by Kalender et al (22), all RBC parameters tested except $\mathrm{MCH}$ were altered in rats exposed to diazinon compared with in an untreated group at 1, 4 and 7 weeks after treatment. A study on the effects of Basudin $600 \mathrm{EW}$ (an active substance of diazinon) in common carp fish (Cyprinus carpio L.) demonstrated that this compound did not exert significant effect on $\mathrm{MCV}, \mathrm{MCH}$ or MCHC, but significantly decreased leukocyte and lymphocyte count while increasing the absolute count of developmental forms of neutrophile granulocytes including myelocytes and metamyelocytes (41). Another similar study conducted by Ahmad (43) highlighted the effect of diazinon exposure toxicity in common carp, manifested as increases in $\mathrm{RBC}, \mathrm{Hb}$ and Hct. Effects of diazinon on the hematological parameters of fry rainbow trout (Oncorhynchus mykiss) have also been revealed, in that sub-lethal doses of the OP substance led to a significant decrease in $\mathrm{RBC}$ and $\mathrm{Hb}$, and increased $\mathrm{MCV}$ and $\mathrm{MCH}$ in a diazinon-exposed group in comparison with untreated groups (42). The results of a study by Yassa et al (44) indicated a significant decrease in $\mathrm{Hb}$ concentration and RBC number in a diazinon group from the third week of the experiment compared with levels in untreated rats. Banaee et al (45) identified that diazinon treatment caused an increase in $\mathrm{RBC}, \mathrm{Hb}$ and Hct parameters while decreasing $\mathrm{MCV}$ and $\mathrm{MCH}$ compared with in an untreated group in common carp. Various doses of diazinon led to reduction in RBC count, Hb concentration and other indices including Hct, $\mathrm{MCV}, \mathrm{MCH}$ and $\mathrm{MCHC}$ in fingerling European catfish (Silurus glanis L.) in an investigation performed by Köprücü et al (46). Additionally, other studies have also demonstrated alterations in hematological indices in different species including rat (47), African catfish (Clarias gariepinus) (48) and Indian carp [Cirrhinus mrigala (Hamilton)] (49).

Regarding improvements to the current study, extending the number of rats in each experimental group, using higher 
doses of TBHQ, and assessment of oxidative stress-related markers by methods including monitoring of their gene expression patterns may be useful in further investigations to acquire more comprehensive and conclusive results.

Nevertheless, the present data suggest that TBHQ as a novel synthetic antioxidant could not efficaciously attenuate the effects of sub-lethal exposure of diazinon on hematological indices in male Wistar rats, despite attenuating certain red cell indices affected by diazinon. The use of higher doses of TBHQ may be necessary to acquire a more convincing outcome.

\section{Acknowledgements}

The authors are thankful to Dr Mostafa Heidarzadegan for his assistance with the study.

\section{Funding}

This study was supported by Ferdowsi University of Mashhad (Mashhad, Iran).

\section{Availability of data and materials}

The datasets used and/or analyzed during the current study are available from the corresponding author on reasonable request.

\section{Authors' contributions}

SS designed the experiment protocol and established the structure and content of the manuscript. HG analyzed the data. SS and SZ wrote the first draft of the manuscript. HG and SS contributed to the writing of the manuscript and verified the manuscript results and conclusions. $\mathrm{HG}$ and $\mathrm{SZ}$ made critical revisions and approved the final version. All authors reviewed and approved the final manuscript.

\section{Ethics approval and consent to participate}

All animal protocols were approved by the Animal Welfare Committee of the School of Veterinary Medicine, Ferdowsi University of Mashhad (Mashhad, Iran).

\section{Consent for publication}

Not applicable.

\section{Competing interests}

The authors declare that they have no competing interests.

\section{References}

1. Sharma P, Jha AB, Dubey RS and Pessarakli M: Reactive oxygen species, oxidative damage, and antioxidative defense mechanism in plants under stressful conditions. J Botany 2012: 217037, 2012

2. Machlin LJ and Bendich A: Free radical tissue damage: Protective role of antioxidant nutrients. FASEB J 1: 441-445, 1987.

3. Ayala A, Muñoz MF and Argüelles S: Lipid peroxidation: production, metabolism, and signaling mechanisms of malondialdehyde and 4-hydroxy-2-nonenal. Oxid Med Cell Longev 2014: $360438,2014$.

4. Beckman KB and Ames BN: Oxidative decay of DNA. J Biol Chem 272: 19633-19636, 1997.
5. Bokelmann I and Mahlknecht U: Valproic acid sensitizes chronic lymphocytic leukemia cells to apoptosis and restores the balance between pro- and antiapoptotic proteins. Mol Med 14: 20-27, 2008.

6. Higashi Y, Noma K, Yoshizumi M and Kihara Y: Endothelial function and oxidative stress in cardiovascular diseases. Circ J 73: 411-418, 2009.

7. Stadler K: Oxidative stress in diabetes. In: Diabetes: An Old Disease, a New Insight. Ahmad S (ed). Springer-Verlag New York, NY, pp272-287, 2013.

8. Apel K and Hirt H: Reactive oxygen species: Metabolism, oxidative stress, and signal transduction. Annu Rev Plant Biol 55: 373-399, 2004.

9. El-Shenawy NS, El-Salmy F, Al-Eisa RA and El-Ahmary B: Amelioratory effect of vitamin $\mathrm{E}$ on organophosphorus insecticide diazinon-induced oxidative stress in mice liver. Pestic Biochem Physiol 96: 101-107, 2010.

10. Shah MD and Iqbal M: Diazinon-induced oxidative stress and renal dysfunction in rats. Food Chem Toxicol 48: 3345-3353, 2010.

11. Eddleston M, Street JM, Self I, Thompson A, King T, Williams N, Naredo G, Dissanayake K, Yu LM, Worek F, et al: A role for solvents in the toxicity of agricultural organophosphorus pesticides. Toxicology 294: 94-103, 2012.

12. Soltaninejad K and Shadnia S: History of the use and epidemiology of organophosphorus poisoning. In: Basic and Clinical Toxicology of Organophosphorus Compounds. Springer, New York, NY, pp25-43, 2014.

13. Casas E, Bonilla E, Ducolomb Y and Betancourt M: Differential effects of herbicides atrazine and fenoxaprop-ethyl, and insecticides diazinon and malathion, on viability and maturation of porcine oocytes in vitro. Toxicol In Vitro 24: 224-230, 2010.

14. Rodrigo L, Hernández AF, López-Caballero JJ, Gil F and Pla A: Immunohistochemical evidence for the expression and induction of paraoxonase in rat liver, kidney, lung and brain tissue. Implications for its physiological role. Chem Biol Interact 137: 123-137, 2001.

15. Sargazi Z, Nikravesh MR, Jalali M, Sadeghnia H, Anbarkeh FR and Mohammadzadeh L: Gender-related differences in sensitivity to diazinon in gonads of adult rats and the protective effect of vitamin E. Int J Womens Health Reprod Sci 3: 40-47, 2015.

16. Aluigi MG, Angelini C, Falugi C, Fossa R, Genever P, Gallus L, Layer PG, Prestipino G, Rakonczay Z, Sgro M, et al: Interaction between organophosphate compounds and cholinergic functions during development. Chem Biol Interact 157-158: 305-316, 2005.

17. Buyukokuroglu ME, Cemek M, Yurumez Y, Yavuz Y and Aslan A: Antioxidative role of melatonin in organophosphate toxicity in rats. Cell Biol Toxicol 24: 151-158, 2008.

18. Lu XT, Ma Y, Wang C, Zhang XF, Jin DQ and Huang CJ: Cytotoxicity and DNA damage of five organophosphorus pesticides mediated by oxidative stress in $\mathrm{PC} 12$ cells and protection by vitamin E. J Environ Sci Health B 47: 445-454, 2012.

19. Colović MB, Krstić DZ, Lazarević-Pašti TD, Bondžić AM and Vasić VM: Acetylcholinesterase inhibitors: Pharmacology and toxicology. Curr Neuropharmacol 11: 315-335, 2013.

20. Aygun D, Erenler AK, Karatas AD and Baydin A: Intermediate syndrome following acute organophosphate poisoning: Correlation with initial serum levels of muscle enzymes. Basic Clin Pharmacol Toxicol 100: 201-204, 2007.

21. Kalender S, Uzun FG, Durak D, Demir F and Kalender Y: Malathion-induced hepatotoxicity in rats: The effects of vitamins C and E. Food Chem Toxicol 48: 633-638, 2010.

22. Kalender Y, Uzunhisarcikli M, Ogutcu A, Acikgoz F and Kalender S: Effects of diazinon on pseudocholinesterase activity and haematological indices in rats: The protective role of vitamin E. Environ Toxicol Pharmacol 22: 46-51, 2006.

23. Banaee M, Sureda A, Mirvaghefi A and Ahmadi K: Effects of diazinon on biochemical parameters of blood in rainbow trout (Oncorhynchus mykiss). Pestic Biochem Physiol 99: 1-6, 2011.

24. Kalender S, Ogutcu A, Uzunhisarcikli M, Açikgoz F, Durak D, Ulusoy Y and Kalender Y: Diazinon-induced hepatotoxicity and protective effect of vitamin $\mathrm{E}$ on some biochemical indices and ultrastructural changes. Toxicology 211: 197-206, 2005.

25. Rush T, Liu XQ, Hjelmhaug J and Lobner D: Mechanisms of chlorpyrifos and diazinon induced neurotoxicity in cortical culture. Neuroscience 166: 899-906, 2010.

26. Sargazi Z, Nikravesh MR, Jalali M, Sadeghnia HR, Rahimi Anbarkeh F and Mohammadzadeh L: Diazinon-induced ovarian toxicity and protection by vitamins E. Iranian J Toxicol 8: 1130-1135, 2014. 
27. Oruç EÖ and Usta D: Evaluation of oxidative stress responses and neurotoxicity potential of diazinon in different tissues of Cyprinus carpio. Environ Toxicol Pharmacol 23: 48-55, 2007.

28. Gokalp O, Buyukvanlı B, Cicek E, Ozer MK, Koyu A, Altuntas I and Koylu H: The effects of diazinon on pancreatic damage and ameliorating role of vitamin $\mathrm{E}$ and vitamin $\mathrm{C}$. Pestic Biochem Physiol 81: 123-128, 2005.

29. Ogutcu A, Uzunhisarcikli M, Kalender S, Durak D, Bayrakdar F and Kalender Y: The effects of organophosphate insecticide diazinon on malondialdehyde levels and myocardial cells in rat heart tissue and protective role of vitamin E. Pestic Biochem Physiol 86: 93-98, 2006.

30. Meyer AS and Isaksen A: Application of enzymes as food antioxidants. Trends Food Sci Technol 6: 300-304, 1995.

31. Sargazi S, Moghadam-Jafari A and Heidarpour M: Protective effect of tert butyl hydroquinone on diazinon-induced oxidative stress in brain and heart of male rats. Zahedan J Res Med Sci 18 $1-5,2016$.

32. Tasset I,Pérez-De La Cruz V, Elinos-Calderón D, Carrillo-Mora P, González-Herrera IG, Luna-López A, Konigsberg M, PedrazaChaverrí J, Maldonado PD, Ali SF, et al: Protective effect of tert-butylhydroquinone on the quinolinic-acid-induced toxicity in rat striatal slices: Role of the Nrf2-antioxidant response element pathway. Neurosignals 18: 24-31, 2010.

33. Nishizono S, Hayami T, Ikeda I and Imaizumi K: Protection against the diabetogenic effect of feeding tert-butylhydroquinone to rats prior to the administration of streptozotocin. Biosci Biotechnol Biochem 64: 1153-1158, 2000.

34. Sanders HO and Cope OB: Toxicities of several pesticides to two species of cladocerans. Trans Am Fish Soc 95: 165-169, 1966.

35. Nasrabadi T, Bidhendi GN, Karbassi A, Grathwohl P and Mehrdadi N: Impact of major organophosphate pesticides used in agriculture to surface water and sediment quality (Southern Caspian Sea basin, Haraz River). In: Environmental Earth Sciences. Vol 63. Springer, New York, NY, pp873-883, 2011.

36. Garfitt SJ, Jones K, Mason HJ and Cocker J: Exposure to the organophosphate diazinon: Data from a human volunteer study with oral and dermal doses. Toxicol Lett 134: 105-113, 2002.

37. Castillo LE, Ruepert C and Solis E: Pesticide residues in the aquatic environment of banana plantation areas in the north Atlantic zone of Costa Rica. Environ Toxicol Chem 19: 1942-1950, 2000.

38. Galloway $\mathrm{T}$ and Handy R: Immunotoxicity of organophosphorous pesticides. Ecotoxicology 12: 345-363, 2003.
39. Kahl R and Kappus H: Toxicology of the synthetic antioxidants BHA and BHT in comparison with the natural antioxidant vitamin $\mathrm{E}$. Z Lebensm Unters Forsch 196: 329-338, 1993 (In German).

40. Hawkey CM, Bennett PM, Gascoyne SC, Hart MG and Kirkwood JK: Erythrocyte size, number and haemoglobin content in vertebrates. Br J Haematol 77: 392-397, 1991.

41. Svoboda M, Luskova V, Drastichova J and Žlabek V: The effect of diazinon on haematological indices of common carp (Cyprinus carpio L.). Acta Vet Brno 70: 457-465, 2001.

42. Far MS, Roodsari HV, Zamini A, Mirrasooli E and Kazemi R: The effects of diazinon on behavior and some hematological parameters of fry rainbow trout (Oncorhynchus mykiss). World J Fish Mar Sci 4: 369-375, 2012.

43. Ahmad Z: Acute toxicity and haematological changes in common carp (Cyprinus carpio) caused by diazinon exposure. Afr J Biotechnol 10: 13852-13859, 2011.

44. Yassa VF, Girgis SM and Abumourad IM: Potential protective effects of vitamin $\mathrm{E}$ on diazinon-induced DNA damage and some haematological and biochemical alterations in rats. J Mediterr Ecol 11: 31-39, 2011

45. Banaee M, Mirvaghefi AR, Mojazi AB, Rafiee GR, Nematdost B: Hematological and histopathological effects of diazinon poisoning in common carp (Cyprinus carpio). Iranian J Nat Resources 64: 1-12, 2011.

46. Köprücü SŞ, Köprücü K, Ural MȘ, İspir Ü and Pala M: Acute toxicity of organophosphorous pesticide diazinon and its effects on behavior and some hematological parameters of fingerling European catfish (Silurus glanis L.). Pestic Biochem Physiol 86: 99-105, 2006.

47. Messarah M, Amamra W, Boumendjel A, Barkat L, Bouasla I, Abdennour C, Boulakoud MS and Feki AE: Ameliorating effects of curcumin and vitamin $\mathrm{E}$ on diazinon-induced oxidative damage in rat liver and erythrocytes. Toxicol Ind Health 29: 77-88, 2013.

48. Nwani CD, Okeke OC, Onyishi G, Atama C, Chinekwu U and Eneje LO: Toxicity and effects of diazinon on behaviour and some haematological parameters of African catfish Clarias gariepinus. Zool Ecol 22: 246-253, 2012.

49. Rauf A and Arain N: Acute toxicity of diazinon and its effects on hematological parameters in the Indian carp, Cirrhinus mrigala (Hamilton). Turk J Vet Anim Sci 37: 535-540, 2013. 